\title{
$\begin{array}{ll}\text { Research Square } & \text { Preprints are preliminary reports that have not undergone peer review. } \\ \text { They should not be considered conclusive, used to inform clinical practice, }\end{array}$ or referenced by the media as validated information. \\ Detecting Impacts of Surface Development Near Weather Stations Since 1895 in the San Joaquin Valley of California
}

\section{Diane Kim}

The University of Alabama in Huntsville

John R. Christy ( $\square$ christy@nsstc.uah.edu )

The University of Alabama in Huntsville https://orcid.org/0000-0001-7883-5903

\section{Research Article}

Keywords: Detecting impacts, surface development, weather stations, San Joaquin Valley of California, Temperature, climate, extreme measurements

Posted Date: October 25th, 2021

DOI: https://doi.org/10.21203/rs.3.rs-865546/v1

License: (c) (i) This work is licensed under a Creative Commons Attribution 4.0 International License.

Read Full License 
1 Detecting impacts of surface development near weather stations since 1895 in the San Joaquin

Valley of California

3

4

5

6

${ }^{1}$ The University of Alabama in Huntsville, ${ }^{2}$ Duke University

8

Corresponding Author: John Christy (christy@nsstc.uah.edu)

9

10

11

12

13

14 
17 Abstract

19 Temperature readings observed at surface weather stations have been used for detecting changes in climate due to their long period of observations. The most common temperature metrics recorded are the daily maximum (TMax) and minimum (TMin) extremes. Unfortunately,

22 influences besides background climate variations impact these measurements such as changes in

23 (1) instruments, (2) location, (3) time-of-observation and (4) the surrounding artifacts of human

24 civilization (buildings, farms, streets, etc.) Quantifying (4) is difficult because the surrounding

25 infrastructure, unique to each site, often changes slowly and variably and is thus resistant to 26 general algorithms for adjustment. We explore a direct method of detecting this impact by

27 comparing a single station that experienced significant development from 1895 to 2019, and

28 especially since 1970, relative to several other stations with lesser degrees of such development

29 (after adjustments for the (1) to (3) are applied.) The target station is Fresno, California (metro 30 population $\sim 15,000$ in 1900 and $\sim 1$ million in 2019) situated on the eastern side of the broad, flat 31 San Joaquin Valley in which several other stations reside. A unique component of this study is 32 the use of pentad (5-day averages) as the test metric. Results indicate that Fresno experienced $33+0.4{ }^{\circ} \mathrm{C} \mathrm{decade}^{-1}$ more nighttime warming (TMin) since 1970 than its neighbors - a time when 34 population grew almost 300\%. There was little difference seen in TMax trends between Fresno 35 and non-Fresno stations since 1895 with TMax trends being near zero. A case is made for the use of TMax as the preferred climate metric relative to TMin for a variety of physical reasons.

37 Additionally, temperatures measured at systematic times of the day (i.e. hourly) show promise as 38 climate indicators as compared with TMax and especially TMin (and thus TAvg) due to several complicating factors involved with daily extreme measurements.

41 Introduction

43 To address the widely-publicized issue of calculating the magnitude of the response of the 44 climate system to human-caused increases in greenhouse gases (GHGs) it is fundamentally 45 necessary to utilize observations which describe what has happened to the climate system from 
periods before and during the period of rising GHGs. Surface temperature is de facto one of the

47 key variables because observations are available back into the $19^{\text {th }}$ century before the response of

48 the climate system to extra GHGs would have been significant. While possessing the key trait of

49 providing a long-term record of a climate-response variable, it is one that is unfortunately

50 confounded by other signals since it also responds to non-GHG effects, e.g. urbanization, and the

51 vagaries due to changes in equipment, observing practices, exposure, time-of-observation, and

52 location (Thorne et al. 2011 and citations therein). Not to be overlooked is a more fundamental

53 confounding factor in that the essential character of the climate system is its non-linear

54 dynamical behavior, having the capability to generate long-term variations without the need for

55 external forcing, such as GHGs, which can naturally cause excursions outside of those observed

56 in our relatively short record of $\sim 125$ years.

57

58 Numerous studies have delved into the complex issues raised by the fact surface temperature

59 observations are beset by numerous inhomogeneity issues. Many of these problems are not well-

60 characterized, so that they render the construction of a century-scale perfectly "pristine" time

61 series essentially impossible though many homogenization methods have been attempted (e.g.

62 Karl et al. 1986, Parker 1994, Christy et al. 2006, Menne and Williams, 2009 and Williams et al.

632012 and citations therein). Indeed, there is a vast body of literature in which many methods of

64 data-adjustment are published to deal with "extraneous biases" in these temperature datasets

65 (e.g., McKitrick and Michaels 2007).

67 In this study we shall describe the unadjusted datasets we utilized and then the adjustments that

68 were necessarily applied in an attempt to remove the specific inhomogeneities due to sudden

69 events such as instrument and location changes. It is important to note that only limited

70 documentation is available regarding the changes in instruments, exposures and practices. Yet

71 even when available this information does not tell us what the impact such changes have on the

72 temperature metric itself. As a result, we must use objective techniques to detect temperature

73 shifts which arise from events which may or may not be documented. From this will be produced

74 an adjusted time series for Fresno from which the estimated impact of urbanization will be

75 calculated, which is the goal of this study. (Note we refer to our changes as "adjustments" rather

76 than "corrections" because we are never certain of their complete accuracy.) 
78 Of particular novelty in this project is the use of the pentad time-scale as the temporal metric.

79 By averaging the daily values into pentads (5-days) we reduce the noise of high-frequency

80 weather variations as well as the random error associated with measurements such as these.

81 Additionally, the annual cycle is more accurately determined as there are 73 representative points

82 rather than the typical 12 monthly points. There were 9125 pentads in the 125 years covering

831895 to 2019 . Another new approach is introduced with the use of hourly data, available back to

841893 in Fresno.

Data Sources

The National Center for Environmental Information (NCEI) houses the largest archive of climate data in the world. Much of the information originally recorded on paper forms has been manually keyed into computer-readable digital files. Such archives have provided access to data

91 for studies that in the last century would have taken enormous amounts of time just to put the

92 data in useable form. After examining time series of about 50 stations, we selected in addition to 93 Fresno, fifteen nearby stations, Angiola, Clovis (near), Friant, Hanford, Le Grand, Lemon Cove, 94 Lindsay, Madera, Merced, Newman, Porterville, Reedley, Tulare, Visalia, and Wasco (Fig. 1).

95 These fifteen stations were selected based on the availability of a relatively long period of data, 96 their proximity to Fresno and that they also reside in the floor of the San Joaquin Valley. The 97 metric we employ will be the extreme daily temperatures commonly known as the daily high 98 (TMax) and daily low (TMin).

100 Of particular interest is that three stations, Clovis-near (1916-1947), Reedley (1895-1920) and 101 Tulare (1895-1906) were not available as computer readable files. The daily observations for 102 these three stations were manually keyed-in from images of the original documents archived at 103 NCEI and provided important information for the early period - a total of 49,541 daily values 104 otherwise not available from NCEI. Details of these stations is provided in the book "Is it 105 getting hotter in Fresno ... or not?" by the second author in which a different method of dataset 106 construction was applied to a different set of stations than utilized in this investigation (Christy 107 2021). The data availability is shown in Fig. 2. 
Method

111 In the methodology that follows we introduce an assumption that the weather records in Fresno

112 were measured and reported accurately. Fresno was an official Weather Bureau/National

113 Weather Service station from the late 1800's, was provided with standard instrumentation, was

114 staffed with federal observers and recorded readings for the calendar day, i.e., midnight to

115 midnight. We will consider Fresno the target station for our analysis. Though the temperatures

116 were measured and recorded in degrees Fahrenheit, we shall convert all to degrees Celsius.

118 The unadjusted data present many challenges for studies such as this. Our first task was to account for time-of-observation bias in the non-Fresno stations. Some observations were recorded in the morning at $0700 \mathrm{~h}$, others in the afternoon around $1800 \mathrm{~h}$ and Fresno (with other

121 stations when they were moved to airports) at midnight. However, documentation regarding the 122 time-of-observation is often missing, so we used a statistical method to determine at what time123 of-day the observation was likely taken and made adjustments accordingly. In this process we 124 are attempting to convert the non-midnight station values to values as would have been observed 125 had the station been a midnight station - in this way we may compare stations having reduced 126 the uncertainty due to this feature.

128 The main issue here is that a station reading TMax and TMin for the past 24 hours at $0700 \mathrm{~h}$ will, 129 in the vast majority of cases, be recording TMax that occurred the previous day. Observations 130 taken at $1800 \mathrm{~h}$ will likely capture the same TMax and TMin as the midnight station since the 131 values of TMax and TMin generally occur between $0000 \mathrm{~h}$ of the day in question and current late 132 afternoon. Though this is not always the case as TMax and TMin may occur at any hour of the 133 day, the dominate time for TMax is mid-afternoon and for TMin, near sunrise. Thus, as we 134 adjust the readings, we realize they will not produce a correct calendar day (i.e., midnight observation) representation in every case.

137 To address this issue for the $0700 \mathrm{~h}$ stations, we compared the daily TMax values of each station 138 to the target station, Fresno, whose observations were consistently recorded at midnight. Using a 
139 fifteen-day window, we generated the correlations between daily TMax values of Fresno against 140 each of the fifteen stations. For each station, we then shifted the window back by one day and 141 again calculated the correlation between Fresno's TMax values and the station's shifted values.

142 [Note: we are using daily values, not pentads.] If the correlations between Fresno and the shifted 143 window were higher than the correlations between Fresno and the non-shifted window for a set 144 period of time, then the observations in that station must be shifted back in order to account for 145 the time of observation bias. Thus, for each month, we shifted TMax values back by one day if

146 their correlations with Fresno were higher since this most likely indicated the station took 147 observations around $0700 \mathrm{~h}$.

Issues related to observations at $1800 \mathrm{~h}$ will be addressed through the removal of breakpoint biases. For example, an observer recording at $1800 \mathrm{~h}$ will read the highest temperature measured in the previous $24 \mathrm{~h}$, i.e., from $1800 \mathrm{~h}$ the day before to $1800 \mathrm{~h}$ today. If the preceding day was hot, i.e., the value at $1800 \mathrm{~h}$ was hot, followed by a cold front later in the evening, the highest temperature attained after the front's passage on the following calendar day would be much cooler. Yet, the observer would read a TMax value that had been attained at $1800 \mathrm{~h}$ the day before when the thermometer was reset rather than the TMax that would have occurred since midnight as recorded in the Fresno station. This "double-counting" of hot days for $1800 \mathrm{~h}$ stations creates a bias in TMax values and the intent will be that it be removed during the

After these adjustments, we then performed an outlier-removal sweep to clear the dataset of 161 highly unlikely temperature readings. This was done by calculating the mean and standard 162 deviation of the set of temperature values for each day of the calendar year, converting the actual 163 temperature anomaly (specific value minus mean for that calendar day) to a z-score (anomaly 164 divided by standard deviation.) We then checked the value of the z-score of the station against 165 the z-score of Fresno for the same day. This was performed separately for TMax and TMin. If 166 the z-score was greater than 2.5 and the difference in z-scores was greater than 2, the non-Fresno 167 station data value was set to missing. Note that we are removing anomalies which not only have 168 a z-score of 2.5 or more, but also whose z-score difference with Fresno exceed the value of 2. 169 This check alerted us, for example, to several erroneous values that appeared to have been 
170 keyed-in without the tens digit for TMin values. Since single-digit values (degrees Fahrenheit)

171 have never been observed in Fresno, and the difference versus Fresno was typically on the order

172 of $20^{\circ} \mathrm{F}\left(11^{\circ} \mathrm{C}\right)$ or more, these were obvious candidates for elimination.

173

174 To make the data more manageable and useful to our purpose, we generated pentad (5-day) mean

175 values as our fundamental test metric. We thus had 73 pentads per year with 29 Feb in Leap

176 Years included as a sixth observation in the $12^{\text {th }}$ pentad. Difference time series for each station

177 relative to Fresno were then calculated (station minus Fresno) to quantify the magnitude of the

178 differences, and their changes over time. Since the raw difference series are not an accurate

179 measure of true climate-induced changes (there are still inhomogeneities to remove) several

180 more statistical adjustments were necessary before seeking patterns in the data.

182 Due to each station's unique microclimate, adjustments for location-induced biases were needed.

183 To this end we generated the mean annual cycle of each time series, using a Fourier Series to 184 create a smooth approximation of each curve, and subtracted from the processed time series their 185 corresponding annual cycles to allow for a more direct comparison of the stations. In Fig. 3 we 186 show the actual mean annual cycle of TMax and TMin of daily values for Fresno as well as the 187 Fourier approximation which was used to generate the time series of anomalies. In Figs. 4a and $1884 \mathrm{~b}$ are the Fourier-smoothed mean annual cycle differences between the fifteen comparison 189 stations and Fresno.

The results in Fig. 4a alert us of some regional variations in temperature patterns. Fresno TMin 192 values are always warmer than the other stations, likely for three reasons. Firstly, until 1939, 193 Fresno's official station was mounted on the roofs of various downtown buildings at elevations 194 from 19 to $29 \mathrm{~m}$ above the ground since 1890. As is well-known in meteorology, nighttime 195 temperatures tend to be coldest at ground level as inversions often form due to rapid radiational 196 cooling of the surface after sunset which causes the air near the ground to also cool. This 197 produces a temperature profile that is cooler at the surface than at elevations several meters 198 above (Walters et al. 2007). For locations in the broad San Joaquin Valley, nighttime inversions 199 are present almost every night. Secondly, many of the stations are in lower-lying parts of the 200 valley and subject to cold-air drainage more so than Fresno which sits on a slight ridge between 
201 the San Joaquin and Kings Rivers. The third factor is likely due to Fresno's rapid population

202 growth after World War II and the influence of built-up infrastructure which was able to retain

203 heat as well as inducing vertical mixing, again keeping TMin values warmer than they would be

204 in a natural setting (Karl et al. 1993, Karl et al. 1998, Christy et al. 2006.). An examination of

205 Porterville, for example, which is the coolest station relative to Fresno, suggests all three of these

206 effects are operating; (1) cooler TMin due to Porterville's near-ground-level observations, (2)

207 less urbanization, and (3) Porterville lies near the river bottom of the Tule River system affected

208 by local cold-air drainage whereas Fresno is not.

With regards to TMax (Fig. 4b), Fresno tends to be slightly cooler on average than the other

211 stations. The larger variations, such as Tulare, indicate the thermometer there was likely

212 exposed to sunlight in a less than optimal siting situation, in which the cold season allowed

213 greater direct exposure (i.e., a thermometer under an eve that allowed greater exposure when the

214 sun was lower in the sky). In general, the assumption is that these variations are systematic and

215 thus removed with the usage of anomalies as the test-metric.

217 Adjusting for the differences in rooftop and ground level observations, which for Fresno

218 occurred in July 1939, requires specific information. Griffith and McKee (2000) noted that the

219 temperature measured at rooftop and ground level vary from location to location so that each

220 situation must be uniquely assessed and appropriately adjusted. This was possible for Fresno by

221 using the breakpoint methodology with the several comparator stations.

222

223 Non-Climatic Shifts in Station Observations

225 The goal here is to remove the impact of various incidents causing sudden, non-climatic shifts in 226 the data (i.e. station relocation, change in instrument, moving station from top of building to

227 ground level, etc.). As many of these shifts are undocumented, we chose to utilize a statistical 228 technique to detect breakpoints and adjust each time series based on an intercomparison with 229 other stations. The goal of this is to improve homogeneity of the data, thereby allowing climate230 induced trends to emerge. The procedure we used relied on this test statistic based on the average 231 of the differences $(\mu)$ between stations: 


$$
\begin{aligned}
\tau_{k}= & \Delta\left\{\left[\mu_{k}^{-}(\Delta)-\mu_{k}(2 \Delta)\right]^{2}\right. \\
& \left.+\left[\mu_{k}^{+}(\Delta)-\mu_{k}(2 \Delta)\right]^{2}\right\} / \sigma_{k}(2 \Delta),
\end{aligned}
$$

where $\Delta$ is the half-window time-width of the interval being examined, $\mu_{\mathrm{k}}{ }^{-}\left(\mu_{\mathrm{k}}{ }^{+}\right)$is the mean value of the temperature difference between stations in the first (last) half-window, $\mu_{\mathrm{k}}$ is the

237 mean of the complete $2 \Delta$ window and $\sigma_{\mathrm{k}}$ is the standard deviation of the differences in the $2 \Delta$ 238 window. If the test metric $\tau_{\mathrm{k}}$ exceeds a certain significance threshold $\mathrm{H}$, we identified it as a 239 breakpoint and shift all prior values by the value $\mu_{\mathrm{k}}{ }^{+}-\mu_{\mathrm{k}}{ }^{-}$. The five values of $\mathrm{H}$ used were 200, $240100,75,60,50$ and 35, but the key results of this study are based on the average of the $H$ values 241 of 75 and 60 together (see Haimberger, 2007, Christy et al. 2009 for complete discussion of 242 technique and Christy and McNider 2016 for a discussion of tests on synthetic and reference 243 datasets). Note that the test metric is the time series of the differences between two stations and $244 \mathrm{H}$ values of 100 and 75 correspond to z-scores of approximately 4.0 and 3.5 respectively.

246 We use an iterative process to determine the breakpoints for Fresno and the 15 non-Fresno 247 stations referred to as "Valley". We first order the Valley stations by their data volume. There 248 are 9125 pentads on the 1895 to 2019 period with Fresno reporting all 5 days in all pentads. 249 Lemon Cove reported the most of the Valley stations with 8580 pentads on which all five days 250 were available. Though Tulare reported the least with 756 pentads, its record began in 1895, 251 hence its value in helping to test the earliest period.

253 Breakpoint values were determined and applied in this sequence. The first breakpoint for Fresno 254 was determined by pair-wise comparisons with all of the Valley stations. Each of the fifteen 255 comparisons produced a time series of $\mathrm{H}$ values based on the difference time series between 256 Fresno and the individual Valley stations. The individual Valley time series of $\mathrm{H}$ were averaged 257 from which the maximum value (i.e., most significant) was determined and used as the first 258 breakpoint for Fresno. Fresno was then adjusted to remove this break identified by the average 259 of the Valley stations. Next, this process was applied to Lemon Cove (the station with the most 260 data of the remaining stations) but using the newly adjusted Fresno time series with the other 
261 fourteen unadjusted Valley stations. As before, the average time series of $\mathrm{H}$ was determined

262 from all of the non-Lemon Cove stations to find the maximum $\mathrm{H}$ and then Lemon Cove was

263 adjusted to remove this event.

264

265 The process was repeated for each station using the stations with longer records having their first

266 breakpoint removed and the stations with fewer records not yet having their first breakpoint

267 removed. At the end of this first sweep, all stations have their first breakpoint removed. The

268 process is then repeated to discover the second, third, etc. breakpoints until no more values above 269 the specific $\mathrm{H}$ threshold are found.

270

271 Results

272

273 Figures 5a and 5b display the TMin and TMax time series of the unadjusted annual anomalies for

274 the Fresno and Valley stations. The graphs indicate general variations as well as likely points

275 where discontinuities occur. Because the Valley time series uses 15 stations, the various

276 discontinuities of the individual stations tend to average out, making this time series smoother

277 and closer to what would be expected from an adjusted time series. In contrast, the single station

278 of Fresno shows likely breakpoints in the 1940s and 1970s among other places for TMin as seen

279 in the relative differences between the two time series. In Fig. 5b, early values of Valley TMax

280 are considerably warmer than Fresno during a time when the Fresno station experienced few

281 potential breaks and resided at a higher, cooler rooftop location. Otherwise, the two TMax time

282 series demonstrate good agreement even in their unadjusted states. This is a common feature of

283 surface temperature records in that TMin is the metric most affected by changes versus TMax

284 (Christy et al 2006, McNider et al. 2012, Scafetta 2021).

286 The breakpoint adjustment procedure was applied to each individual station from $\mathrm{H}=200$ to $\mathrm{H}=$

287 35. At $\mathrm{H}=35$ and 50, there were many breakpoints detected, some likely due to the random

288 processes of interstation differences that naturally occur. With $\mathrm{H}=200$, there were no

289 breakpoints detected for Fresno as the significance test allowed only extremely significant

290 breakpoints to be accepted. A general rule is that surface stations of this type experience about

291 one breakpoint per 7 to 15 years (Christy et al. 2006). The values of $\mathrm{H}=60$ and $\mathrm{H}=75$ generated 
292 time series with breakpoint incidences in line with the expected number, thus we shall use the 293 average of these two as that which eliminates (a) mostly true non-climatic breakpoints, and (b) 294 the fewest breakpoints due to natural causes. Detailed discussion of the thresholds for these test 295 metrics is found in Christy and McNider 2016.

297 Figure 6a shows the result for TMin as the adjusted time series of Fresno and the combination of 298 the 15 comparison stations or Valley. Correlations between the two are 0.88 (0.77) for TMin 299 (TMax). Comparing these to the unadjusted correlations of 0.76 (0.43) for TMin and TMax 300 respectively it is clear that the removal of breakpoints has improved the agreement, especially 301 with TMax (Fig. 6b) due to the improvement in the early Valley values.

303 Our interest here is the detection of differences in the long-term temperature change between the 304 two datasets. The 125-year trends for TMin for Fresno (Valley) are $+0.26 \pm 0.14(+0.17$ $305 \pm 0.06){ }^{\circ} \mathrm{C}$ decade $^{-1}$. More relevant are the trends from 1970 to the present, the period in which 306 significant urban growth occurred around the Fresno station. Here the Fresno (Valley) trends are 307 highly significantly different, $+0.63(+0.22)^{\circ} \mathrm{C}$ decade $^{-1}$, suggesting a value of the urban effect 308 of approximately $+0.4{ }^{\circ} \mathrm{C}$ decade $^{-1}$ in the last 50 years - at least a lower bound as the other 309 stations also certainly experienced some urban growth, as well.

311 The values for TMax indicate a very different outcome. For the 125-year period of record, 312 Fresno (Valley) TMax trends are $+0.01 \pm 0.09(-0.05 \pm 0.10){ }^{\circ} \mathrm{C}$ decade $^{-1}$ and since $1970,+0.27$

$313(+0.31){ }^{\circ} \mathrm{C}$ decade $^{-1}$. These differential trends are not statistically different from each other, and 314 for the full 125-year record are not statistically different from zero.

As a partially independent check, we obtained hourly temperatures for Fresno to compute 00UT 317 and 12UT temperature time series representing 0400 and 1600 local standard time. We chose a 318 single month, July, due to its relatively small interannual variability and the significant effort that was required to manually key-in the data.

321 The use of hourly data avoids the time-of-observation problem in which extreme daily 
323 the fact different stations recorded TMax and TMin for differing 24-h periods. As well, the more

324 complicated mechanical issues (indexes that ride on top or underneath the column of liquid that

325 often malfunction) and digital aspects (variable time constants to determine extreme

326 temperatures from observations taken at very small intervals) of determining TMax and TMin

327 are completely avoided. Finally, the hourly reading was often read from a different thermometer

328 than the TMax and TMin thermometers, as part of the psychometric calculations, so it is, again, a

329 basically independent check.

330

331 We accessed these hourly values; Downtown Fresno (FNO, WBAN 53125, 1895-1939),

332 Chandler Field (FCH, WBAN 23167, 1933-1949) and the Fresno-Yosemite International Airport

333 (FAT, WBAN 93193, 1949 to present). FNO recorded temperatures at 0500/1700 (01UT/13UT)

334 local standard time (LST), FCH at LST 0442/1642 (0042UT/1242UT) and FAT at 0400/1600

335 (00UT/12UT). The conversion to 00UT/12UT was accomplished through the interpolated

336 difference calculated from FAT temperatures, where all hours of the day in the last few decades

337 were recorded. For example, in July, the average 12UT temperature was $0.63{ }^{\circ} \mathrm{C}$ warmer than

$33813 \mathrm{UT}$ at FAT, thus $0.63{ }^{\circ} \mathrm{C}$ was added to $\mathrm{FNO}$ and $0.44{ }^{\circ} \mathrm{C}$ to $\mathrm{FCH}$ readings to convert 0500 and

3390442 respectively to account for their later (slightly cooler) observation times. An additional

340 shift was applied to account for the FNO's rooftop observations based on six years of

341 overlapping data with FCH, and for FCH's ground-level but urbanized site (Christy 2021).

343 The results are shown in Fig. 7 and resemble major aspects of the annual values in Figs 6a,b.

344 There is a period of relatively cooler readings in the middle of the 00UT (1600 LST) time series

345 and a clear upward trend which accelerated after 1970 in 12UT (0400 LST). The adjusted Jul

346 hourly time series produced 1895-2019 trend values of $+0.42(+0.02){ }^{\circ} \mathrm{C}$ decade $^{-1}$ for $12 \mathrm{UT}$

347 (00UT). We note that this is an exploratory test because a single month cannot be expected to

348 reproduce the values calculated for the annual time series in Figs. 6a,b - note in particular the

349 annual values after 2012 are much higher than seen in July-only and were due to anomalous heat

350 in spring and fall months. In any case, this result provides a potentially new source of

351 observations that may be useful for climate analysis due to its inherent advantages over the

352 vagaries that affect observations of TMax and TMin. 
Discussion

Through the years, surface temperature data have been recorded through times of substantial 357 changes in instrumentation, surroundings and practices. These changes often impact the record 358 in ways that produce discontinuities for assessing long-term changes, not to mention the slowly 359 evolving impacts of increasing infrastructure surrounding the stations. As noted earlier, many investigators have identified the sudden inhomogeneities in recent decades and attempted to 361 produce adjustment algorithms so that a more useful time series unaffected by these changes could be studied.

In this investigation we use the novel approach of defining the temporal extent of the metric as 5day periods, or pentads. In this way we reduce random noise of the daily metric for better statistical treatment of the analysis here performed. Requiring that all 5 days be present for the pentad calculation improves over typical studies which use monthly data but allow a number of missings to be acceptable. And, with 73 periods per year, the resolution of the annual cycle is more precisely determined for anomaly calculation.

371 We use a more-or-less classical approach for determining breakpoints, but have selected a 372 procedure that focusses on a single station, Fresno, in a method that attempts to isolate its long373 term change relative to the long-term changes of the remaining, much less urbanized stations 374 nearby. The results indicate there is little difference between Fresno and non-Fresno stations for 375 the metric of TMax. However, in the past 50 years of Fresno's rapid urban expansion, the TMin 376 change is three times that of the other stations, many of whom likely have experienced unnatural 377 warming from their own growth.

379 As explained in numerous studies, (e.g., Oke 1973, Oke et al. 1991, Nair et al. 2011, McNider et 380 al. 2012, Christy et al. 2013, Scafetta 2021), the natural nocturnal cooling of urban areas (i.e. 381 TMin) is inhibited by several factors which have much less influence on TMax. TMax is 382 measured, in general, in mid-afternoon after the surface has been heated for several hours, 383 creating deep vertical atmospheric mixing (1 to $2 \mathrm{~km}$ and more in depth) of the boundary layer 384 which among other things allows the surface temperature to attain more of the character of a 
large mass of the atmosphere. Horizontal winds are of greater magnitude above the surface, so

386 the vertical motions also mix these downward expanding the sphere of influence of a surface

387 thermometer even more. Thus, nearby stations with differing urbanization levels have greater

388 affinity with one another in the afternoons through the deep vertical and horizontal mixing of the 389 boundary layer air down to the surface.

The nocturnal boundary layer, in which TMin is usually observed, is altogether different. As the 392 surface cools at night, the air becomes dense and separates (decouples) from the deep atmosphere above often being a layer only a few meters deep as a nighttime inversion occurs. This cold air does not represent the character of much warmer air above.

This shallow, cold layer is somewhat delicate and can be readily disturbed so that the much warmer air above mixes down to keep the surface temperature warmer than it would have been in the undisturbed state. Factors that create such disturbances include the presence of buildings as they disrupt the horizontal winds above the shallow, cold layer, forcing a mechanical mixing of the warmer air above down to the surface. Then, certain surfaces which absorb more heat than the natural ground cover will release that heat through the night, creating enough vertical mixing to prevent a full decoupling of the potentially cold surface from the warmer air above. Further, atmospheric constituents such as thermal-absorbing aerosols or greenhouse gases serve to retard the cooling rate of the surface thus retarding the formation of the cold, decoupled surface layer (Nair et al. 2011). Note that in all of these cases, there is not an accumulation of more heat that affects the station, but a redistribution of heat (McNider et al. 2012). The end

The results we see here for Fresno and the Valley are consistent with this well-established

410 boundary-layer theory. For the broad atmospheric mass as observed in mid-afternoon (TMax)

411 the values of the trends suggest there has been no significant change in the long-term

412 temperature time series for Fresno $\left(+0.01{ }^{\circ} \mathrm{C}\right.$ decade $\left.^{-1}\right)$ nor for the Valley $\left(-0.05{ }^{\circ} \mathrm{C}\right.$ decade $\left.^{-1}\right)$

413 since 1895. NOAA/NCEI uses a different algorithm which, for example, incorporates stations

414 further from Fresno for breakpoint detection and fewer nearby as is done here. Their resulting

415 TMax (TMin) 125-year trends through 2019 are $+0.03(+0.23){ }^{\circ} \mathrm{C} \mathrm{decade}^{-1}$, being within error 
416 limits of our calculations and support the lack of atmospheric warming as indicated by TMax and

417 significant warming of the urban nocturnal boundary layer at night (TMin).

419 However, since 1970, the NCEI analysis for Fresno diverges from trends in this study which 420 calculated TMax (TMin) trends as $+0.27(+0.63){ }^{\circ} \mathrm{C} \mathrm{decade}{ }^{-1}$, while those of NCEI are +0.44

$421(+0.36){ }^{\circ} \mathrm{C} \mathrm{decade}^{-1}$ (accessed 11 Jun 2021, NCEI values tend to change as processing algorithms 422 are updated). In the period after 1970, our method detected several breakpoints due to

423 relocations, some to accommodate construction at the air terminal, as well as installation of new 424 equipment. Note, our TMax analysis is corroborated by the combined Valley station time series 425 for this period. Evidently, the combination of our breakpoint adjustments versus those of NCEI 426 in the last 50 years produces differing 50-year trends as indicated. There is clear evidence that 427 nights have warmed significantly compared with days in this region in the past 50 years (e.g. 428 Christy et al. 2006, Christy 2021 as well as Figs. 5a,b and 7 in our study), so this 50-year 429 difference poses a question for further study. Indeed, we are at a loss to explain how the raw 430 data can be adjusted to produce a TMax trend greater than TMin from 1970 to 2019. However, 431 for the 125-year period, the differing breakpoint adjustments between ours and NCEI tended to 432 essentially average out to near zero in their impact on the long-term trend.

434 The relative strong upward trend since 1970 for both Fresno and Valley in TMax (about $+0.3^{\circ} \mathrm{C}$ 435 decade $^{-1}$ ) is likely a coincidence in that the beginning of this 50-year period was quite cool and 436 that the worst regional drought in 130 years occurred near its end (2012-2016). The types of 437 drought-causing stagnant high-pressure systems are not unusual and lead to both higher 438 temperatures and lower precipitation. Indeed, in this climate, such drought periods of up to 100 439 years have occurred in the past when lakes in the neighboring Sierra Nevada Mountains receded 440 so far and for so long that forests were established on the exposed lake bottoms. Today their 441 drowned trunks are now submerged (in Lake Tahoe see Lindstrom, 1990 and in Fresno County 442 see Morgan and Pomerleau, 2012). We note that the TMax trend for Fresno (Valley) for 18954431970 was $-0.08(-0.20){ }^{\circ} \mathrm{C}$ decade $^{-1}$, so a rebound from this decline would be a statistically-likely 444 expectation. 
446 Regarding the possible effect of increasing greenhouse gases, this rapid warming of TMin 447 relative to TMax was not reproduced in the recent CMIP-6 climate model simulations. We 448 accessed 28 CMIP-6 surface temperature time series for the conterminous US and their average

449 result for 1970-2020 indicated the average TMax warmed insignificantly more than TMin $450\left(+0.014{ }^{\circ} \mathrm{C}\right.$ decade $\left.^{-1}\right)$. Of the 28 models, most, (18) produced TMax trends greater than TMin 451 which is opposite of this result found for Fresno. Thus, these simulations support the conclusion 452 that Fresno's rapid rise of TMin relative to TMax is due to factors unrelated to large-scale 453 forcing.

455 It is unfortunate that the two most common climate metrics observed have been the extreme 456 temperatures in a 24-hour period, TMax, TMin, and from them a computed average (TAvg). 457 The ready availability of TAvg has led to it becomomg the metric-of-choice even though it 458 represents a convoluted indicator of temperature change over land. Studies such as ours should 459 provide encouragement to the climate community to investigate TMax as a preferred long-term 460 indicator of surface temperature change as it represents the deeper atmosphere and is less prone 461 to the vagaries of the formation of the shallow nocturnal boundary layer and localized impacts of 462 urbanization (McNider et al. 2012). As explained, TMin is extremely sensitive to the immediate 463 landscape and its changing character over time and thus is contaminated too easily by these non464 climatic factors.

466 Simply using TMax however does not solve remaining problems associated with (a) urbanization 467 as cities will still be hotter in the day than the countryside, (b) the time-of-observation bias, (c) 468 location changes and (d) instrumental upgrades. With that in mind, it is further recommended 469 that long-term datasets of hourly temperatures be digitized and investigated for use as indicators 470 of climate variability and change as they avoid some of the problems inherent with the extrema 471 of daily temperatures.

473 Conclusion

475 In this investigation we demonstrate a method to improve the surface temperature values for 476 climate studies now based on extremes recorded during 24-h periods. Using the temporal metric 
477 of 5-day averages (pentads) we generated temperatures of the daily extremes (TMax and TMin)

478 for 16 stations in the San Joaquin Valley of California USA in an attempt to document the 479 influence of infrastructure expansion around the largest city in the sample, Fresno, over the 480 period 1895 to 2019. Applying a breakpoint detection and adjustment technique based on 481 statistical significance and intercomparing all stations with each other, we created an adjusted 482 time series of all stations in which these shifts relative to other stations were removed.

484 Comparing Fresno versus the average of the much less-urbanized stations we detected a 485 significant warming in Fresno TMin values, especially over the 50-year period of its largest 486 growth 1970-2019. It is clear that TMin in Fresno has been impacted by urbanization with an 487 estimated effect of at least $+0.4^{\circ} \mathrm{C} \mathrm{decade}^{-1}$ as this is the amount our analysis suggests Fresno 488 has warmed relative to the non-Fresno stations. Since there has likely been some urbanization 489 impact on the non-Fresno stations too, the value of $+0.4{ }^{\circ} \mathrm{C}$ decade ${ }^{-1}$ should be considered a 490 lower bound on the influence of surface development on TMin around Fresno.

492 This result is consistent with boundary-layer theory; TMin occurs in a shallow nocturnal 493 boundary layer that may be systematically disturbed through time, resulting in an increasing 494 tendency for warm air above to be mixed to the surface (i.e., impeding the usual decoupling of 495 the surface cool layer from warm air above). Factors that cause such increased mixing include 496 (a) buildings which disrupt the vertical wind profile to prevent the decoupling between the cool 497 surface layer and the warmer air above, (b) increases in thermal absorbing constituents such as 498 aerosols or greenhouse gases which retard radiational cooling of the surface, and (c) changes in 499 surface type to those more conducive to increasing heat content (e.g. vegetation to concrete) and 500 keeping temperatures warmer through the night than otherwise would be the case. These all 501 interact to redistribute the heat in the vertical profile from higher levels down to the surface, but 502 do not increase the heat content in the total column by a meaningful amount. Since 1970, the 503 trend of the time series of differences TMin minus TMax for Fresno was $+0.36^{\circ} \mathrm{C} \mathrm{decade}^{-1}$. The 504 same metric for the non-Fresno stations was an insignificant $-0.08^{\circ} \mathrm{C}$ decade $^{-1}$, indicating again a 505 warming rate for TMin unrelated to large-scale atmospheric forcing. 
507 The overall TMax trend for Fresno and the non-Fresno stations during the period 1895-2019 was 508 negligible, +0.01 and $-0.05{ }^{\circ} \mathrm{C}$ decade $^{-1}$ respectively with an estimated error of $\pm 0.10{ }^{\circ} \mathrm{C}$ decade $^{-}$

$509{ }^{1}$. This is an indication that the larger scale climate variations have not experienced any unusual 510 change since 1895 in this region. We also demonstrated that there may be value in hourly

511 readings of temperature as they avoid some of the convoluted impacts on the metrics such as 512 TMax and TMin.

513

514 


\section{Declarations}

518 Compliance with Ethical Standards: The authors declare no conflicts of interest.

Ethics and Consent Forms: N/A. No human or animal subjects were investigated in this

521 research and thus no consent forms are required.

522

523 Conflict of Interest or Competing Interests: Authors declare no conflict of interest or

524 competing interests.

525

526 Funding Statement: Kim - Alabama State Climatologist. Christy, partial funding from the 527 Alabama Office of the State Climatologist and grant funding from U.S. Dept. of Energy DE528 SC0019296. No funding from private entities supported this research and authors have no 529 relevant financial or non-financial interests to disclose.

531 Author's contributions: Kim 55\%, data access, organization, code writing, computation, testing 532 and text writing. Christy $45 \%$, data analysis, text writing, literature search.

534 Data and code availability. The processed data and code will be made available upon request 535 to the corresponding author (christy@nsstc.uah.edu). Publicly available station data used in the 536 construction of the datasets were accessed through three sources:

537 https://www.ncdc.noaa.gov/IPS/coop/coop.html

538 https://www.ncdc.noaa.gov/EdadsV2/ (primarily hourly data which were keyed-in)

539 http://scacis.rcc-acis.org

540

541 Consent to Participate: Both authors consent to participate

542 Consent to Publish: The University of Alabama in Huntsville consents to publish these 543 findings. 
547 References

548

549 Christy, J.R. (2001) When was the hottest summer? A State Climatologist struggles for an

550 answer. Bull. Amer. Meteor. Soc., 83, 723-734.

551

552 Christy, J.R., W.B. Norris, K. Redmond and K.P. Gallo (2006) Methodology and results of

553 calculating central California surface temperature trends: Evidence of human-induced climate

554 change? J. Climate, 19, 548-563.

555

556 Christy, J.R. W.B. Norris and R.T. McNider (2009) Surface temperature variations in East

557 African and possible causes. J. Climate, 22, 3342-3356, DOI:10.1175/2008JCLI2726.1.

558

559 Christy, J.R. (2013) Monthly temperature observations for Uganda. J. Appl. Meteor. Clim., 52, 560 2363-2372. Doi:10.1175/JAMC-D-13-012.1.

561

562 Christy, J.R. and R.T. McNider (2016) Time series construction of summer surface temperatures 563 for Alabama, 1883-2014, and comparisons with tropospheric temperature and climate model 564 simulations. J. Appl. Meteor. Clim., 55, 811-826.

565

566 Christy, J.R. (2021) Is it getting hotter in Fresno ... or not? ISBN 9798714472664. 140pp.

567 Available at Amazon.com.

568

569 Griffith, B.D. and T.B. McKee (2000) Rooftop and ground standard temperatures: A comparison 570 of physical differences. Climatology Report No. 00-2. Paper No. 694. Colorado State

571 University.

572

573 Haimberger, L. (2007) Homogenization of radiosonde temperature time series using innovation 574 statistics. J. Climate, 20, 1377-1403.

575 
576 Karl, T.R., C.N. Williams Jr., P.J. Young and W.M. Wendland (1986) A model to estimate the

577 time of observation bias associated with monthly mean maximum, minimum and mean

578 temperature for the United States. J. Clim. Appl. Meteorol., 25, 145-160, doi:10.1175/1520-

5790450.

580

581 Karl, T.R., H.F. Diaz and G. Kukla (1988) Urbanization, Its detection and effect in the United

582 States climate record. J. Clim., 1, 1099-1123. Doi:10.1175/1520-042(1988)001.

583

584 Karl, T.R., P.D. Jones, R.W. Knight, G. Kukla, N. Plummer, V. Razvayev, K.P. Gallo, J.

585 Lindseay, J.R.J. Charlson and T.C. Peterson (1993) Asymmetric trends in surface temperature,

586 Bull. Am. Meteorol. Soc., 74, 1007-1023.

587

588 Lindstrom, S.G. (1990) Submerged tree stumps as indicators of Mid-Holocene aridity in the

589 Lake Tahoe Basin, J. Calif. And Great Basin Anthro. 12(2).

590

591 McKitrick, R. and P.J. Michaels (2007) Quantifying the influence of anthropogenic surface

592 processes and inhomogeneities on gridded global climate data. J. Geophys. Res., 112, D24S09, 593 doi:10.1029/2007JD008465.

594

595 Menne, J.J. and C.N. Williams, Jr. (2009) Homogenization of temperature series via pairwise

596 comparisons. J. Climate, 22, doi.org/1-.1175/2008JCLI2263.1

597

598 Morgan, C. and M.M. Pomerleau (2012) New evidence for extreme and persistent terminal

599 medieval drought in California’s Sierra Nevada. J. Paleolimnol 47:7070-713. DOI

$60010.1007 / \mathrm{s} 10933-012-9590-9$.

601

602 Nair, U.W., R. McNider, R. Patadia, S.A. Christopher and K Fuller (2011) Sensitivity of

603 nocturnal boundary layer temperature to tropospheric aerosol surface radiative forcing under

604 clear-sky conditions. J. Geophys. Res. 116, Do2205, doi:10.1029/2010JD014068.

605

606 Oke, T. (1973) City size and the urban heat island. Atmos. Env. 7, pp 769-779 
608 Oke, T.R., G.T. Johnson, D.G. Steyn and I.D. Watson (1991) Simulation of surface urban heat

609 islands under 'ideal' conditions at night part 2: Diagnosis of causation. Boundary-Layer

610 Meteorol 56, 339-358. Doi.org/10.1007/BF00119211.

611

612 Parker, D.E. (1994) Effects of changing exposure of thermometers at land stations. Int. J.

613 Climatol., 14, 1-31.

614

615 Scafetta, N. (2021) Detection of non-climatic biases in land surface temperature records by

616 comparing climatic data and their model simulations. Clim. Dyn. Doi.org/10.1007/s00382-021-

617 05626-x.

618

619 Thorne, P.W., K.M. Willett, R.J. Allan, S. Bojinski, J.R. Christy, N. Fox, S. Gilbert, I. Jollieffe, 620 J.J. Kennedy, E. Kent, A.K. Tank, J. Lawrimore, D.E. Parker, N. Rayner, A. Simmons, L. Song, 621 P.A. Stott and B. Trewin (2011) Guiding the creation of a comprehensive surface temperature 622 resource for twenty-first-century climate science. Bull. Amer. Meteor. Soc., 623 DOI:10.1175/2011BAMS3124.1.

624

625 Walters, J.T., R.T. McNider, X Shi, W.B. Norris and J.R. Christy (2007) Positive surface

626 temperature feedback in the stable nocturnal boundary layer. Geophys. Res. Lett, 34, L12709,

627 doi:10.1029/2007/GL029505.

628

629 Williams, C.N., M.J. Menne and P.W. Thorne (2012) Benchmarking the performance of pairwise 630 homogenization of surface temperatures in the United States. J. Geophys. Res., 117, D05116, 631 doi:10.1029/2011JD016761.

632

633 


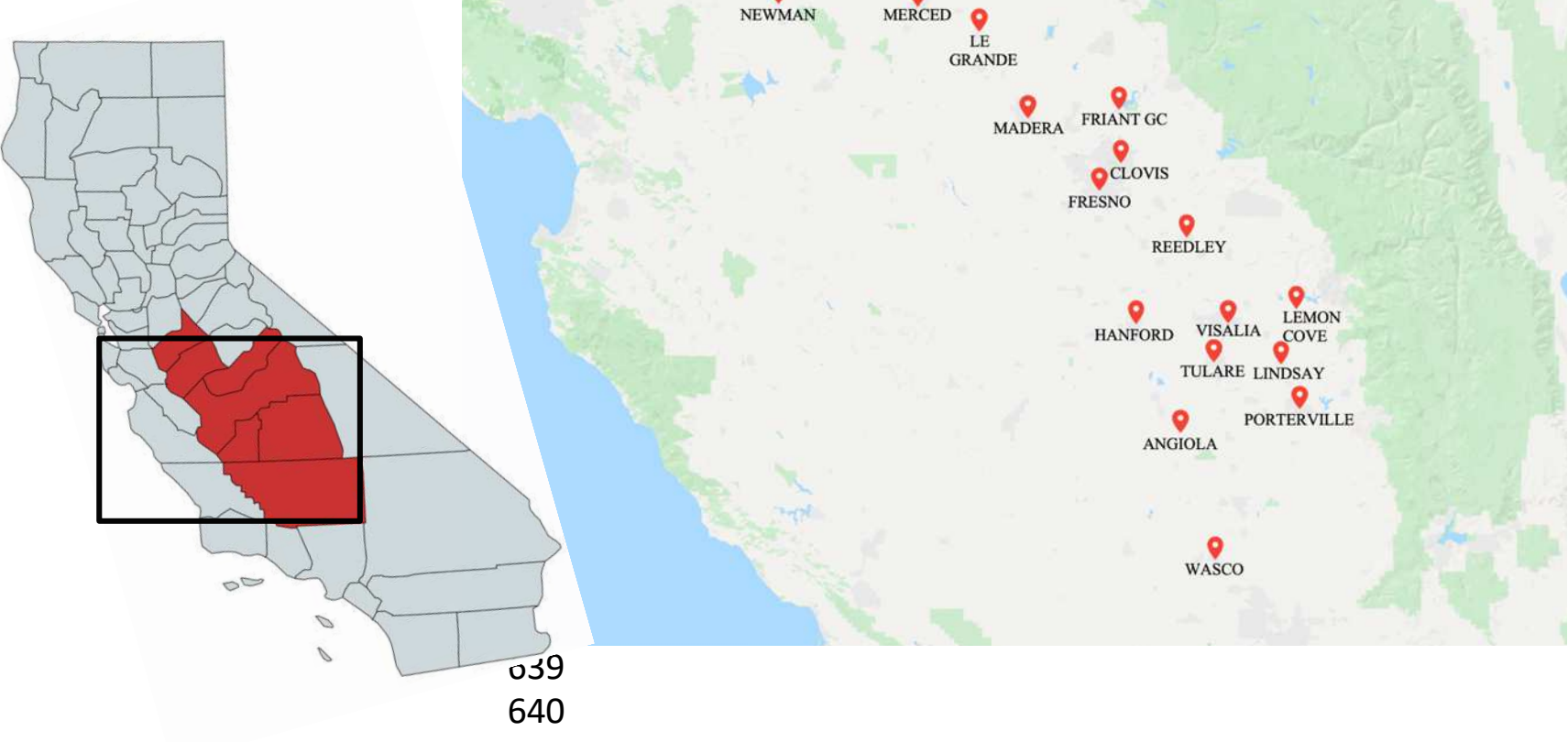

641

642

643 Figure 1 Map of the central San Joaquin Valley of California with stations used in this study.

644

645

646 


\section{Years with $>67 \%$ of Pentads Available}

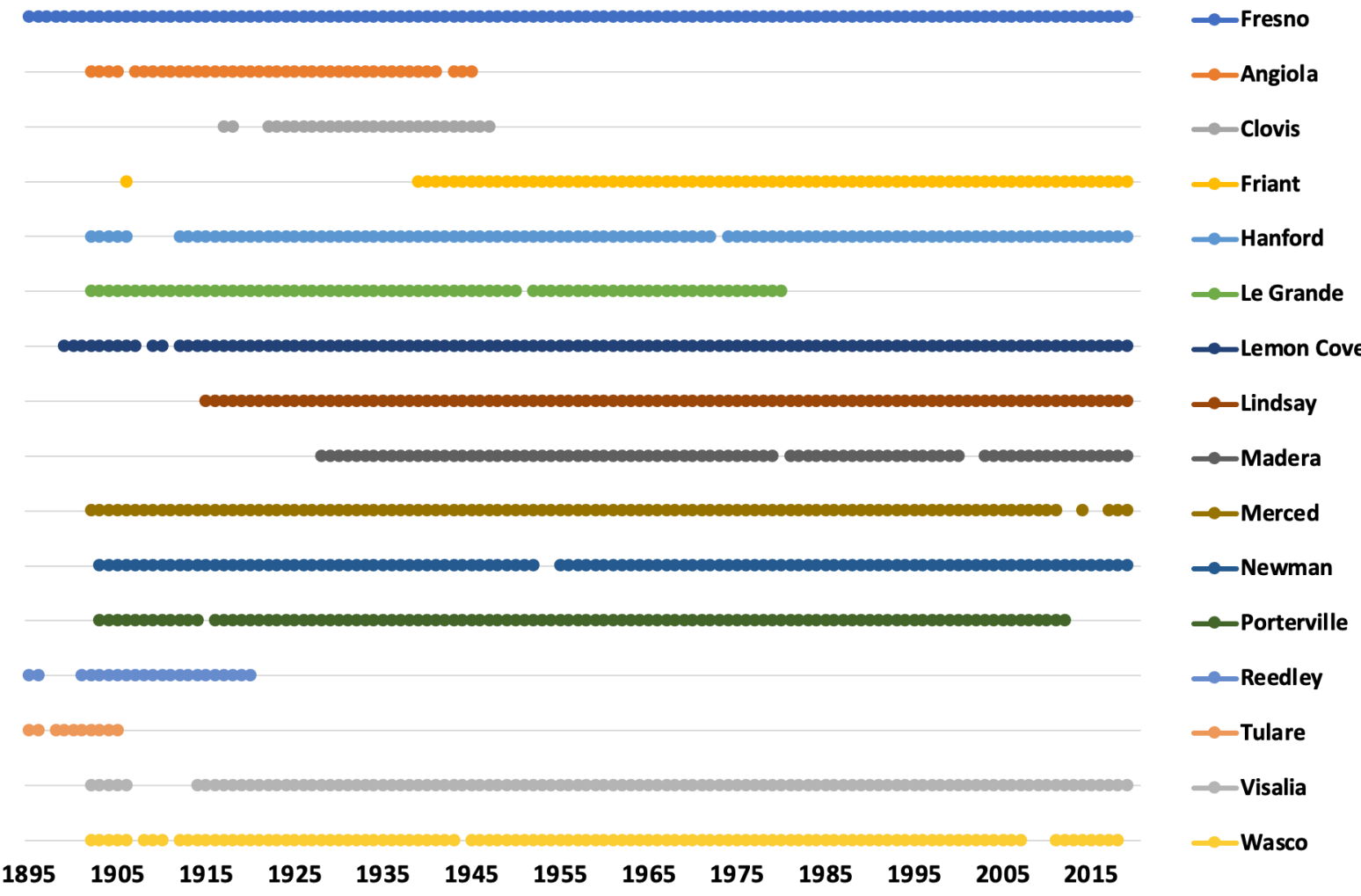

649 Figure 2. Chart of data availability by year. Symbol appears if $>67 \%$ of pentads (at least 49 ) 650 contained all five days of data. 


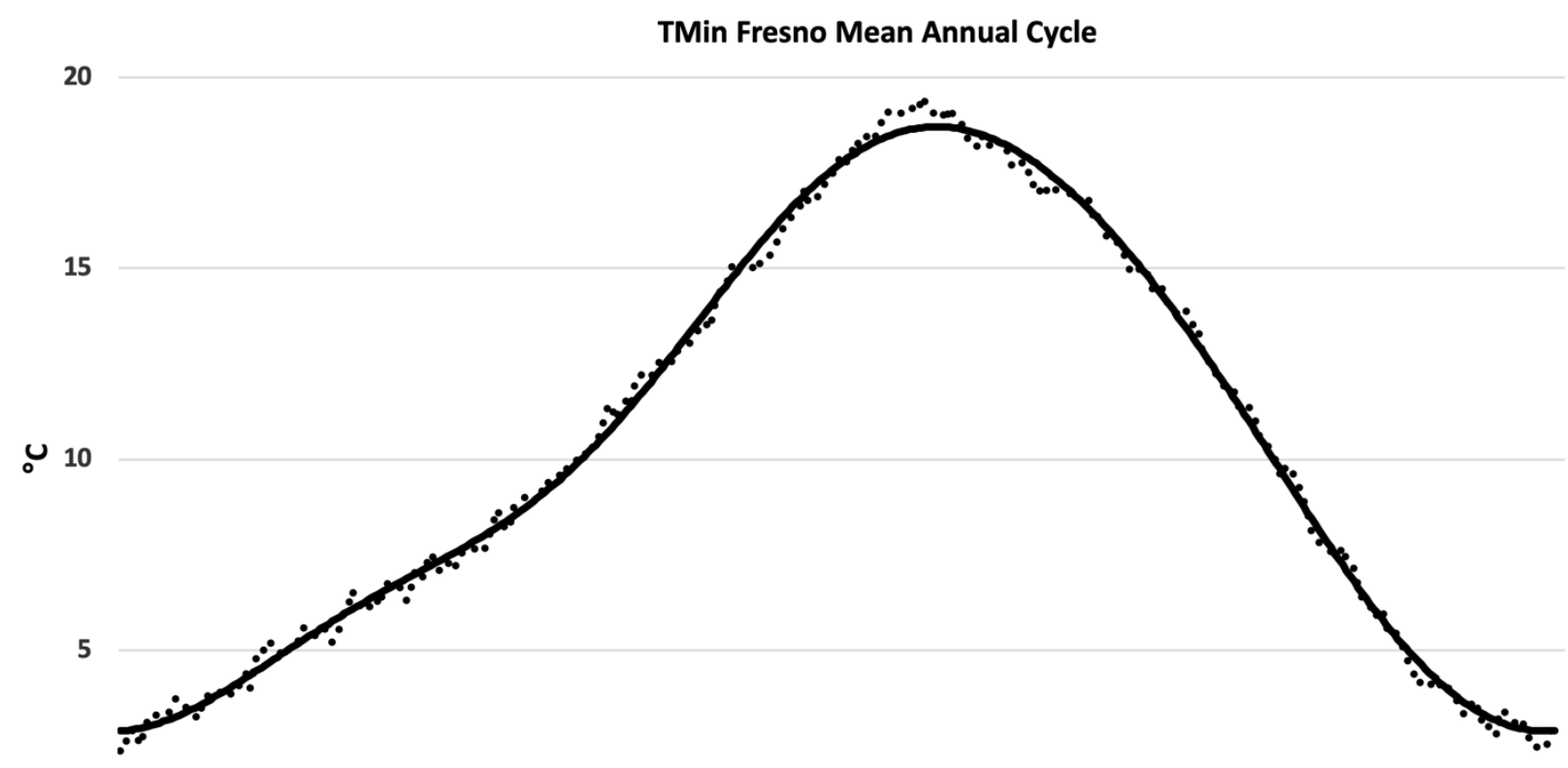

0

\begin{tabular}{|c|c|}
\hline 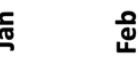 & 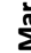 \\
\hline
\end{tabular}

654 Figure 3a Mean annual cycle of daily TMin for Fresno (unadjusted) both unsmoothed and 655 approximated by Fourier analysis which is used for anomaly calculation.

656

657 


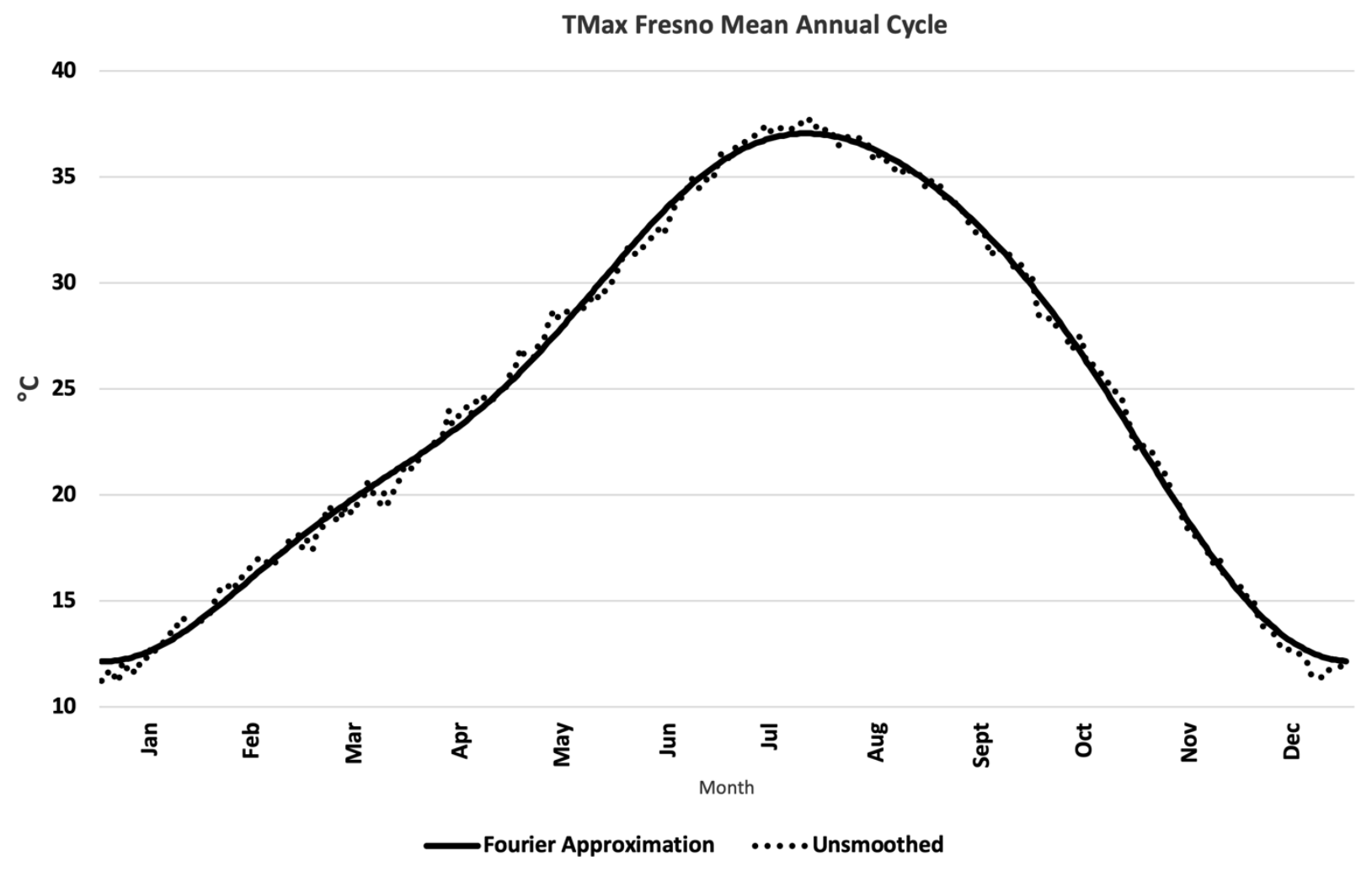

660 Figure 3b Mean annual cycle of daily TMax for Fresno (unadjusted) both unsmoothed and 661 approximated by Fourier analysis which is used for anomaly calculation. 


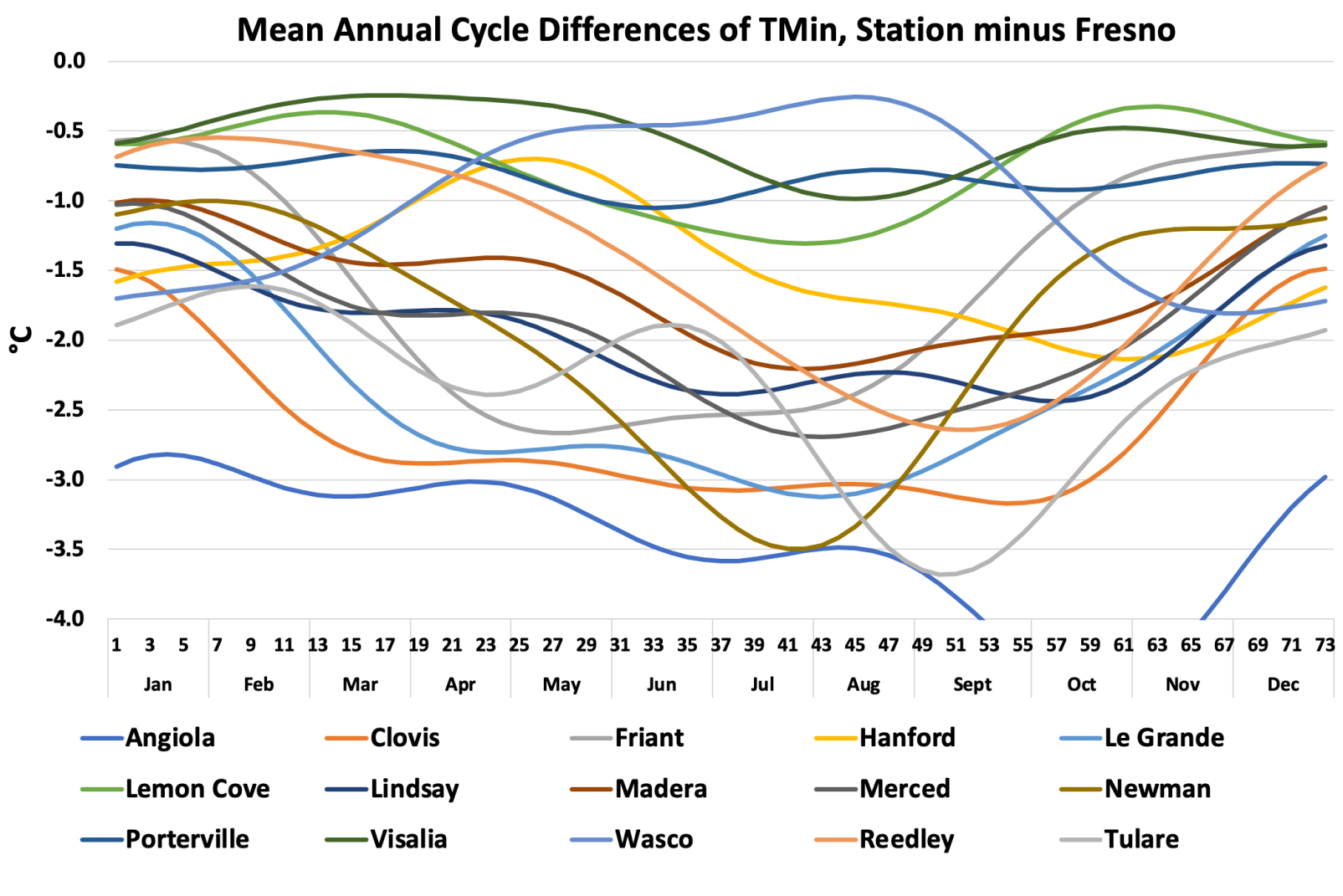

666

667 Figure 4a Difference between mean annual cycle of Fresno and the fifteen comparison stations 668 (station minus Fresno) based on the 73 pentad values.

669

670

671 


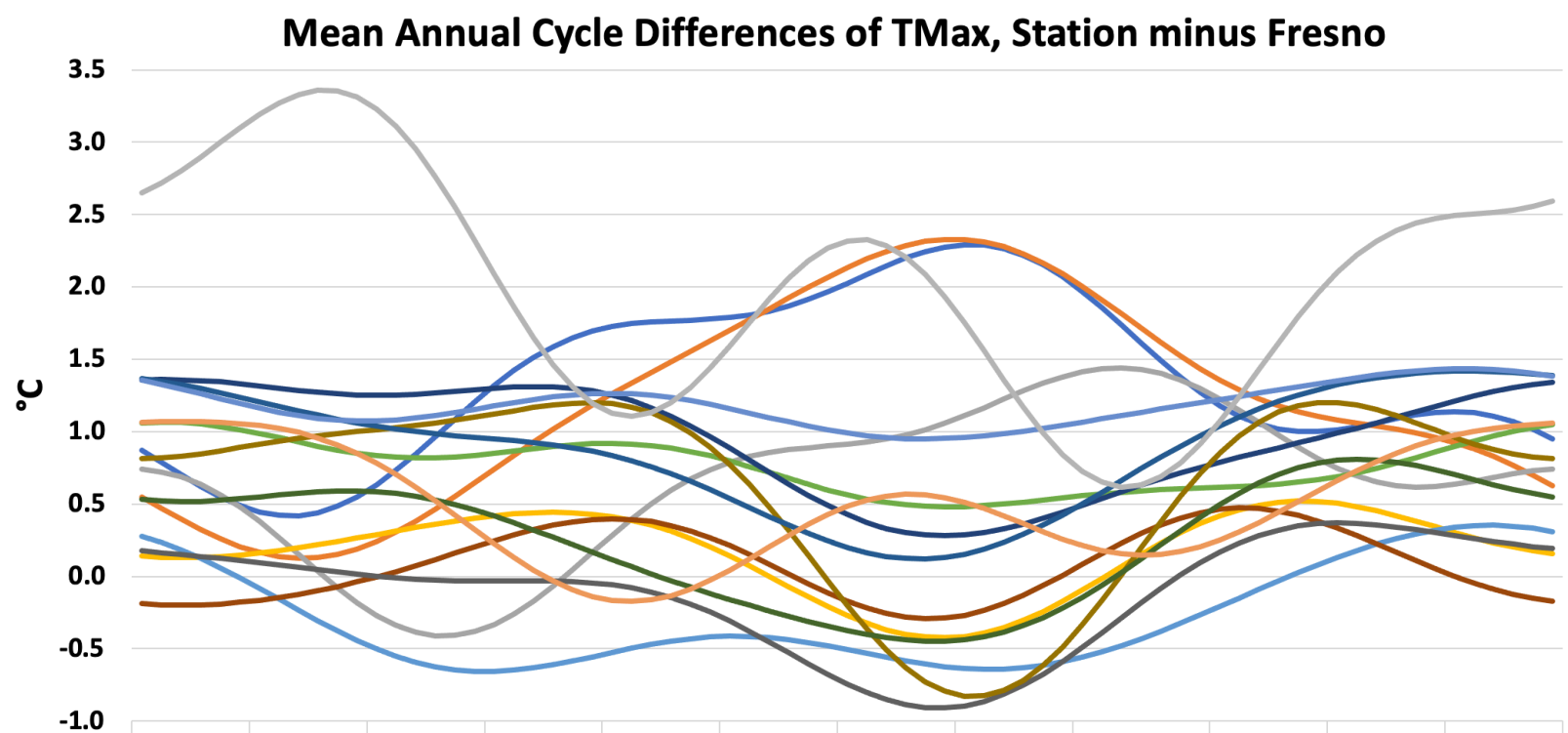

$-1.0$

672

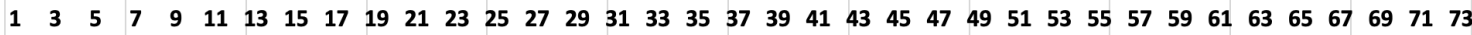

673

674

675

Figure 4b As in Fig. 3a but for TMax. 
676

677

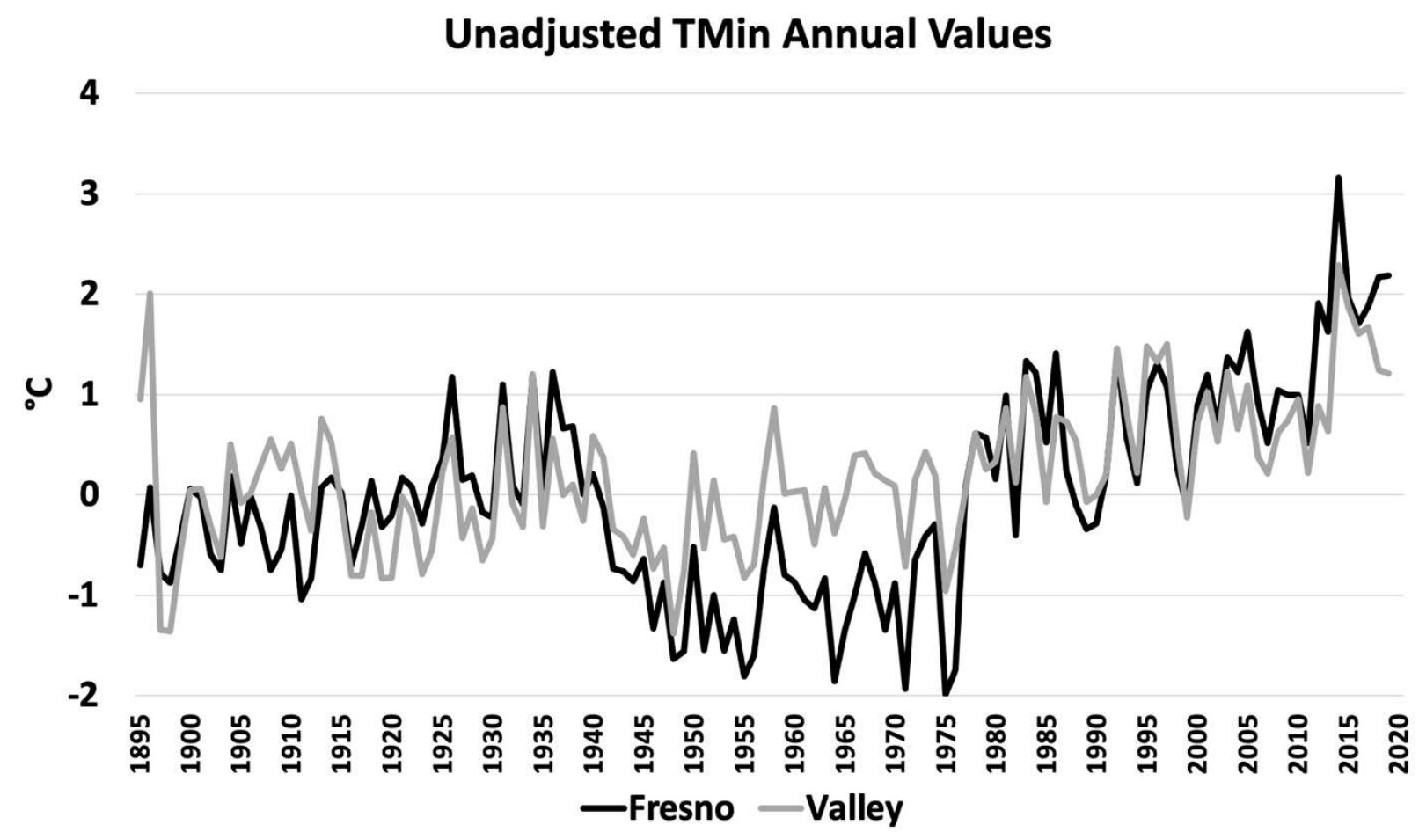

678

679

680

Figure 5a Time series of TMin annual anomalies of the unadjusted Fresno and Valley stations. 


\section{Unadjusted TMax Annual Values}

\section{4}

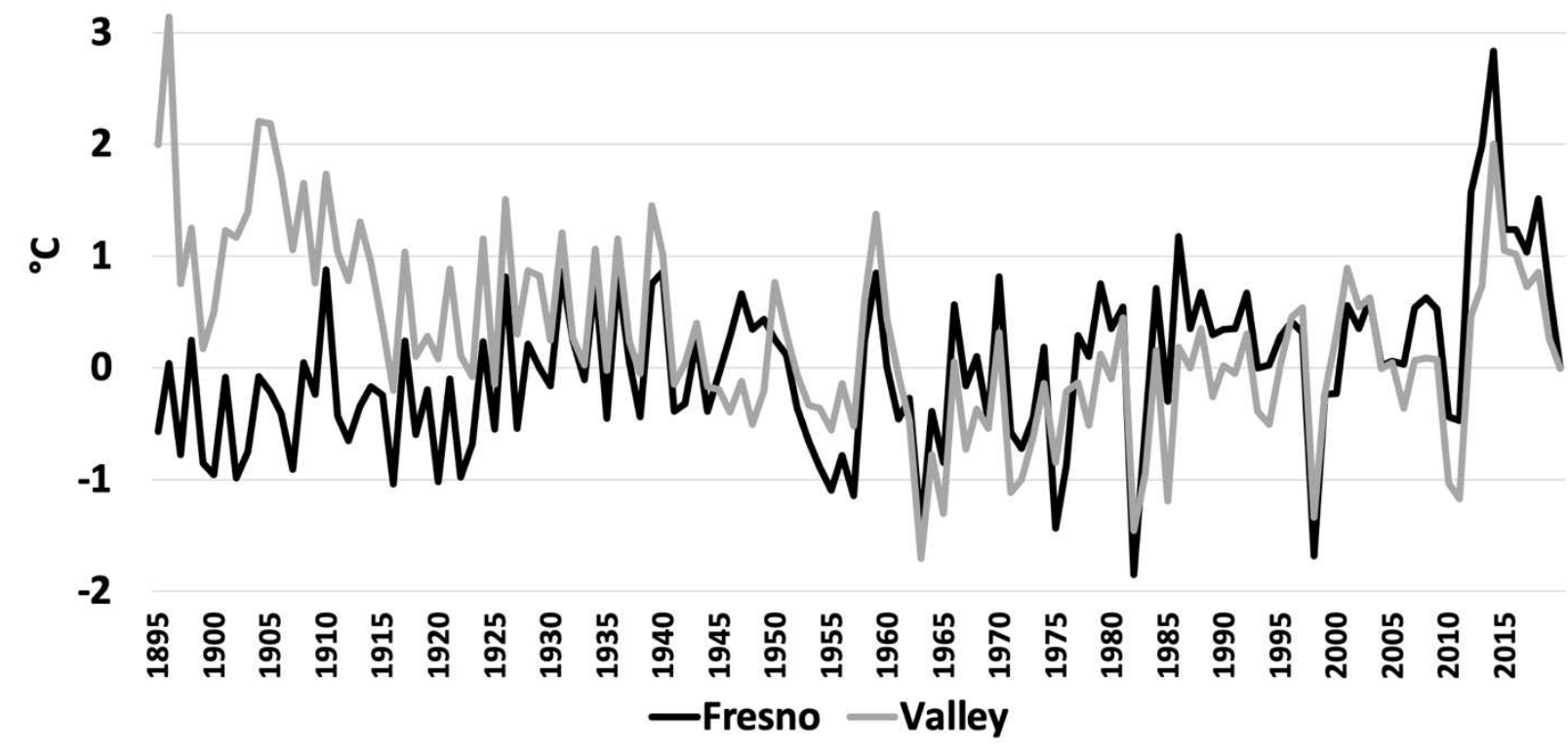

682

683

684

685

686

687

Figure 5b As in Fig. 4a but for TMax. 
Annual TMin Temperature anomalies for Fresno and the average of $\mathbf{1 5}$ Valley Stations using test statistics $\mathrm{H}=\mathbf{6 0}$ and 75

\section{4}

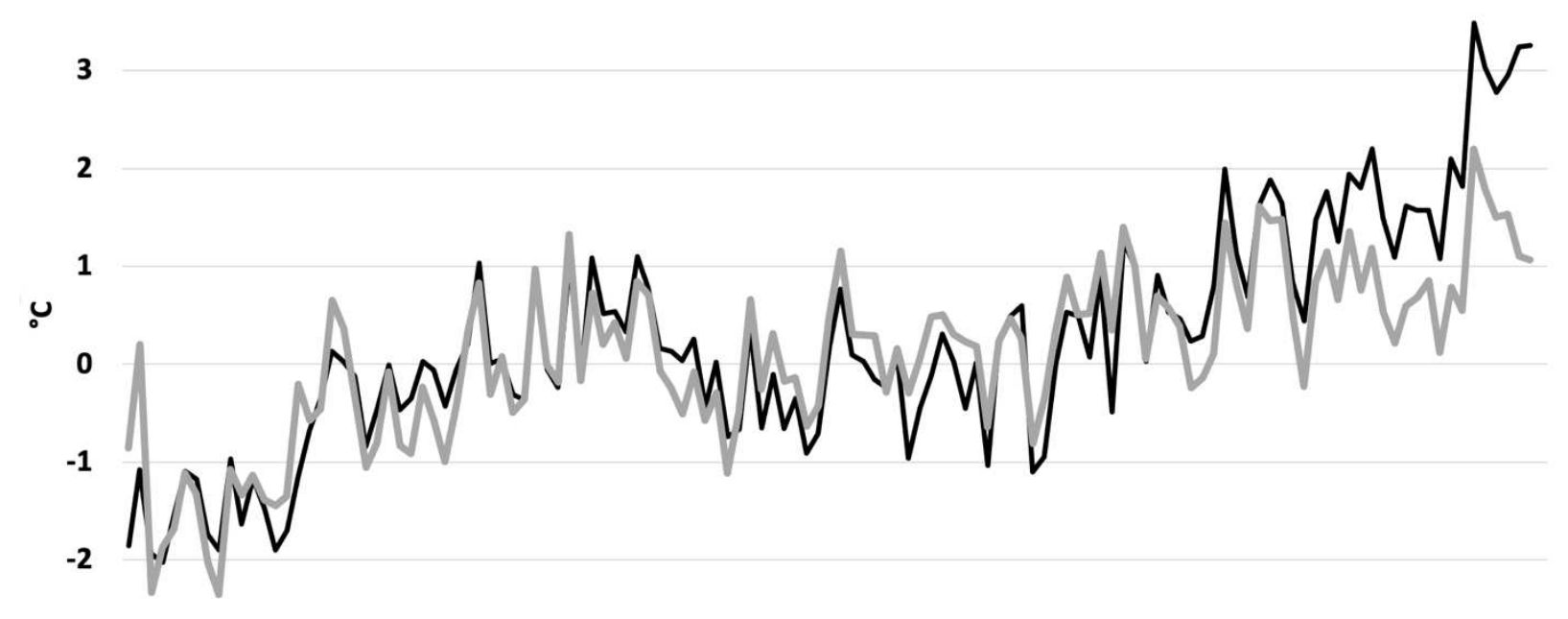

$-3$

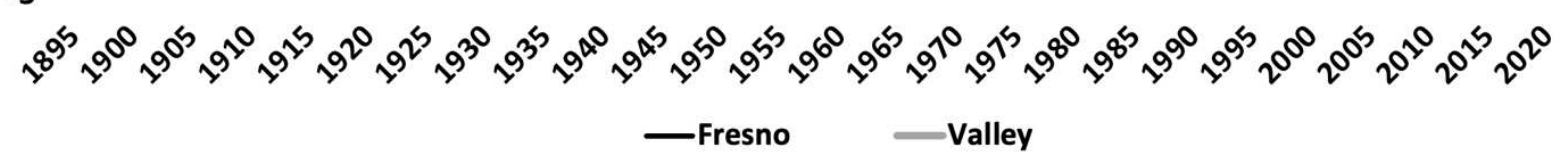

Figure 6a As in Fig. 4a with the adjusted time series as the mean of $\mathrm{H}=60$ and $\mathrm{H}=75$. 


\section{Annual TMax Temperature anomalies for Fresno and the}

average of 15 Valley Stations using test statistics $H=60$ and 75

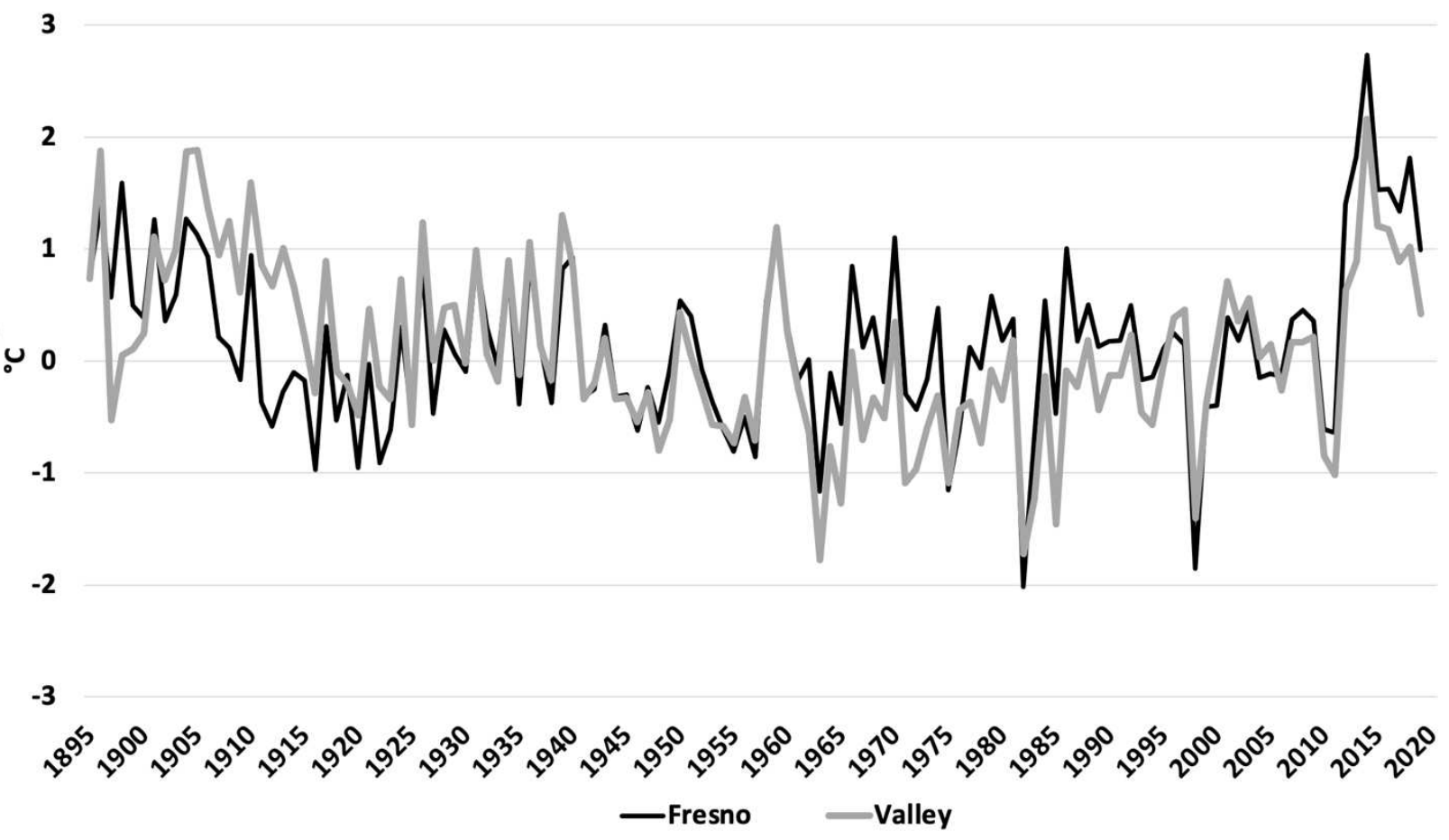

Figure $6 \mathrm{~b}$ As in Fig. 5a but for TMax.

694

695

696

697

698

699

700 
701

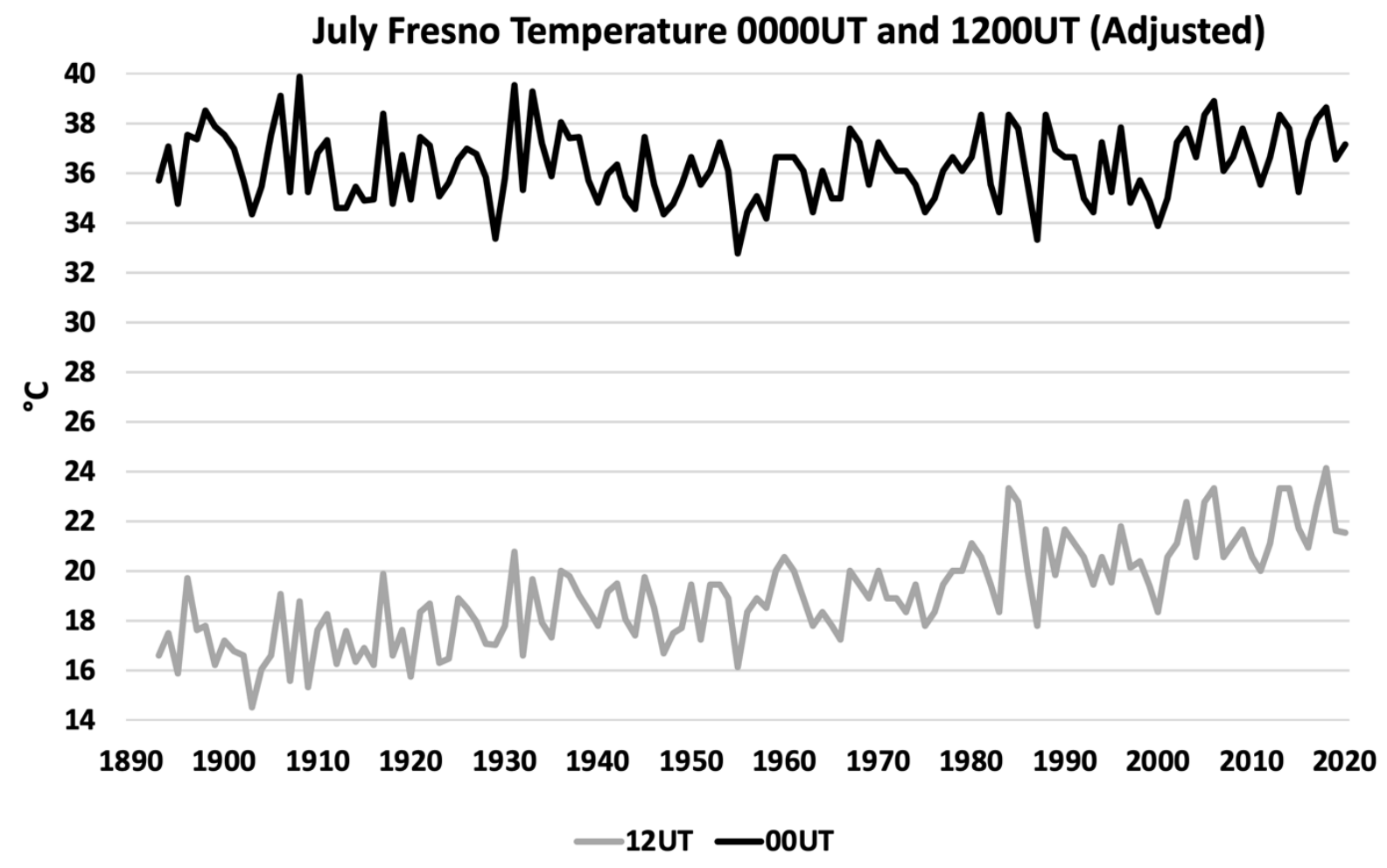

702

703

704 Figure 7 Time series of monthly-averaged hourly values observed at 00UT (1600 LST) and 705 12UT (0400 LST) for July.

706

707

708 